\title{
THE TREATMENT OF HAEMATEMESIS
}

\author{
G. N. Chandler, M.A., D.M., M.R.C.P. \\ Physician, Chapel Allerton Hospital, Leeds and Wakefield Area Hospitals: \\ late Senior Registrar, Department of Gastroenterology, Central Middlesex Hospital, London, N.W.10
}

Haematemesis is one of the commonest medical emergencies that may threaten life. It is the most frequently encountered complication of peptic ulcer, occurring at some time in about $25 \%$ of cases, ${ }^{8}$ and peptic ulcer is easily the most important cause of the admission of patients with severe bleeding from the upper alimentary tract. In Avery Jones' series ${ }^{12}$ of 2,526 admissions for this emergency, 2,298 were due to proved or probable peptic ulcers. Table I shows the distribution of the various causes of bleeding in admissions to the Central Middlesex Hospital for haematemesis and/or melaena between 1940 and I957.

\section{TABle I}

Peptic ulcer group:

$\begin{array}{llllll}\text { Chronic gastric ulcer } & \ldots & \ldots & \ldots & \ldots & 423\end{array}$

$\begin{array}{llllll}\text { Duodenal ulcer .. } & \ldots & \ldots & \ldots & \ldots & 423 \\ & & \ldots & \ldots & \ldots & 844\end{array}$

Post-operative group previous or partial

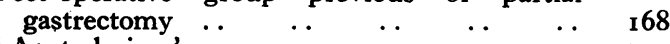

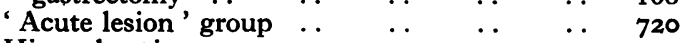

$\begin{array}{lllllll}\text { Hiatus hernia } & \ldots & \ldots & \ldots & \ldots & \ldots & 47\end{array}$

Unclassified (incompletely investigated) $\quad \ldots \quad 96$

2,298

Causes other than peptic ulceration:

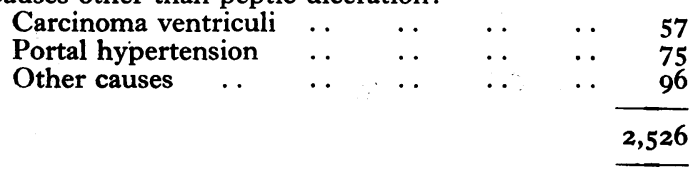

\section{Diagnosis of the Cause of Bleeding}

Though the probability is that the patient admitted after an attack of haematemesis and melaena is bleeding from a benign ulcerative process in the upper alimentary tract, there remains an important group of less common causes including portal hypertension, gastric carcinoma and other tumours of the gastro-intestinal tract, blood dyscrasias, and bleeding associated with the strain of vomiting (Mallory-Weiss syndrome) and general medical diseases such as periarteritis nodosa, uraemia and malignant hypertension. Their recognition is not only an interesting diagnostic challenge but als. an important factor in subsequent management. $\frac{}{8}$

The difficulty of treating bleeding peptic ulces largely concerns the detection of those patients it: whom the prognosis with medical measures muse be considered poor and who will bleed to deatit unless surgery is employed. The problem is not always easily solved. Acute ulceration or erosio of the stomach or duodenum is a common lesion which usually responds well to medical treatment. but this diagnosis is not always obvious, being

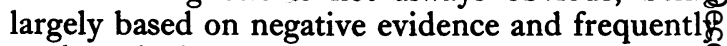
made only in retrospect after a negative X-ray The vessels by which an acute ulcer bleeds are mostly small and submucosal and operation sho@l be undertaken only if there has been severe qees current bleeding on two or three occasions accompanied by shock.

Extra-gastric sources of bleeding must also be excluded before patients are submitted to surgery The history is one of the most valuable aids if achieving a correct diagnosis; thus where chroni peptic ulceration is responsible for the bleeding will be unusual to find such a patient denying previous periodic dyspepsia with food and alkali relief of his pain. The shorter the history of preceding dyspepsia, the more likely is the lesion to be acute and, therefore, best treated medically $\frac{3}{3}$. enquiry as to recent salicylate consumption mà் give a clue to correct diagnosis, but unfortunatel $\overrightarrow{7}$. this is not always obvious and the history may be misleading.

There is thus much need for a method o $\oint$ investigation that will yield diagnostic information in the acute stage of illness, for if chronic peptie. ulceration can be diagnosed with confidencề surgical treatment is to be recommended in patients over the age of 50 who bleed again aftes admission to hospital. At the Central Middlese Hospital the following procedure of early come bined investigation has been adopted. As soon as the patient has been made comfortable afte admission, a Ryle's tube is passed via the nose an\& about $5 \mathrm{ml}$. of gastric contents are aspirated hourlog 
by syringe suction and $\mathrm{pH}$ estimated electrometrically at the end of the intubation period, which finishes at $9 \mathrm{a} . \mathrm{m}$. on the day after admission, when gastroscopy is performed. Later that morning or in the early afternoon of the same day, barium meal examination is done on the ward using a portable $\mathrm{X}$-ray set and without manipulation or the need to move the patient from his bed. By combining the information derived from study of intragastric acidity, $3,4,5$ from gastroscopy, and from early X-ray examination, it has proved possible to achieve a correct diagnosis of the cause of bleeding in $80 \%$ of patients admitted with haemorrhage from peptic ulcer, usually within 24 or 36 hours from admission. ${ }^{6}, 7$ The reliability of the early diagnostic procedures in forecasting correct diagnosis was significantly greater than the clinical impression of the cause of bleeding in each of the three groups of chronic gastric ulcer, chronic duodenal ulcer and acute ulcer.

\section{General Considerations in Treatment}

Though, to a large extent, the correct treatment of haematemesis depends on the diagnostic probabilities established by careful examination and, where possible, confirmed by appropriate investigation, certain general measures apply to all cases of bleeding from the alimentary tract. There is no longer any controversy about the advisability of liberal feeding. Meulengrachts' original diet ${ }^{14}$ has been modified in this country by Witts ${ }^{25}$ and it is this regime that is usually followed; most patients do well on a two-hourly soft diet with fluids as desired between, but if nausea is a prominent complaint then two-hourly milk feeds are sufficient. There is no evidence that such feeding increases the liability to further haemorrhage, the risk of which remains at about $25 \%$ of admissions for bleeding peptic ulcer. ${ }^{12}$ Certainly it is unphysiological to deprive an exsanguinated patient of food and fluid at such a time of special need and there is no doubt that modern treatment has eliminated the deaths which formerly occurred from therapeutic dehydration.

Strict confinement of the patient to bed is essential in the presence of severe or continued bleeding, but there is no reason why the patient whose course is uncomplicated should not be allowed up by the second or third hospital day. There is no evidence to suggest that recovery after haematemesis is hastened by confinement to bed, the dangers of which are enhanced in older patients with associated degenerative diseases. There is little doubt that, in the presence of satisfactory clinical progress, the physician can best serve the interests of his patients by allowing early ambulation, and Pollard and Summerskill ${ }^{18}$ have shown that such a policy confers important benefits.
An injection of sodium phenobarbitone, $200 \mathrm{mg}$., may be required on admission to secure the patients' mental relaxation; occasionally, morphine, ro to $15 \mathrm{mg}$., may be needed for the anxiety and restlessness of shock but medication other than vitamin concentrates and antacids is best avoided, though iron may be given by mouth from the start. Constipation is the rule after haematemesis and is usually well tolerated by the patient. Purgatives should not be administered but there is no objection to the use of a glycerine or 'Dulcolax' suppository. Aspirin should always be avoided and, instead, Panadol given for incidental pains or discomfort.

It is unusual for ulcer pain to persist after haemorrhage has occurred and continued severe pain suggests the possibility of concomitant perforation (a particularly lethal combination) or of an independent cause such as cardiac infarction. A continuous intra-gastric milk drip, giving 6 pints in 24 hours through a small nasal tube, is an extremely valuable treatment if the symptoms of active peptic ulceration recur.

Though brisk continued bleeding from peptic ulcer is an indication for surgical treatment, there are a few patients in whom operation can reasonably be considered as out of the question because of severe associated disease or the features of overwhelming senility. Nevertheless, however unpromising the prognosis may appear, neither hope nor treatment should be abandoned. Distension of the stomach with blood clot may be an important cause preventing the atonic stomach of a shocked patient from arresting the bleeding by contraction. Emptying the stomach with a Senoran's evacuator followed by lavage with icecold water may help to stop bleeding and the use of a topical haemostatic such as thrombin after washing the stomach out with $I: 1,000$ adrenalin has been advocated in the treatment of bleeding acute peptic ulcer. In such cases the stomach should first be emptied through a large-bore tube and then lavaged with $1: 1,000$ adrenalin; finally, thrombin in a suitably viscous vehicle such as methyl cellulose is instilled into the stomach.

\section{Blood Transfusion}

An hourly record should be kept from admission of pulse and blood pressure, and blood immediately taken for haemoglobin or haematocrit and into a plain tube for grouping and cross-matching for transfusion. There can be no hard-and-fast rules as to when blood transfusion is required. Whilst blood volume determinations would enable the clinician accurately to assess the amount of blood lost, such techniques are, as yet, unsuitable for routine use and reasonable working rules for the employment of blood transfusion are a pulse rate 
of 120 or more, a systolic blood pressure of $100 \mathrm{~mm}$. $\mathrm{Hg}$. or less, or if the haemoglobin is below $50 \%$. Tibbs ${ }^{24}$ found that the diastolic blood pressure reflected the diminution in blood volume more accurately than the systolic pressure, except in hypertensive patients who maintain their diastolic pressure better than normals in the presence of bleeding. A diastolic pressure of 60 to $65 \mathrm{~mm}$. $\mathrm{Hg}$. indicated moderate to severe blood loss. Transfused blood does not act as a haemostatic but there is no evidence to suggest that it provokes recurrence of bleeding. It is best regarded as a remedy for haemorrhagic shock and as giving the patient a further margin of safety should he bleed again. Prompt transfusion is particularly important in the elderly to prevent the irreversible cerebral damage that may complicate prolonged shock. If severe anaemia is allowed to develop a compensatory increase in venous pressure leads to greater cardiac filling and improved cardiac output. This hyperkinetic phase presents with a full bounding pulse, raised pulse pressure and jugular venous distension. The venous pressure also rises during the initial stages of transfusion, and though it falls again as the arterial pressure rises, overtransfusion in the hyperkinetic phase carries the risk of precipitating heart failure.

Usually gastro-duodenal bleeding stops within 12 or 24 hours of admission, most often permanently, and during this time 1,500 to $3,000 \mathrm{ml}$. of blood may be given by slow drip transfusion (40 drops per minute). Occasionally there is a continuous slow loss of blood requiring intermittent transfusion and this seems to happen most commonly in patients bleeding from acute lesions; the vessels by which an acute ulcer bleeds are mostly small and submucosal, and such bleeding lacks the dramatic quality of arterial haemorrhage from the base of a chronic ulcer. Exceptionally, chronic ulcers bleed so severely that the only hope for the patient lies in intra-arterial transfusion and immediate operation.

Transfusions of $500 \mathrm{ml}$. are unnecessary and wasteful. Large volumes of blood given rapidly carry risks of citrate intoxication and hyperkalaemia. The former may lead to defective clotting and myocardial failure and it is wise to give $10 \mathrm{ml}$. of $10 \%$ calcium gluconate intravenously after every fourth bottle of blood. Potassium intoxication carries the very real threat of cardiac arrest, particularly if bank blood near the limit of its expiry is used, in which serum potassium levels may reach $25 \mathrm{mEq} / \mathrm{l}^{13}$ Warming the blood before use will encourage the return of potassium to the cells and the danger can be further diminished by the infusion of dextrose solutions. However, when such massive transfusions are in question, the need for surgical arrest of haemorrhage should be urgently re효 viewed.

\section{Surgery of Bleeding Peptic Ulcer}

Though the majority of patients recover under medical management, there is undoubtedly $\overline{\bar{\omega}}$ significant proportion who will bleed to deatb unless surgery is employed. If chronic peptio ulceration can be diagnosed with reasonable confidence, operative treatment is to be recom $\Phi$ mended for those older patients in whom bleeding is severe, or recurs after admission to hospital. As early as 1918, Finsterer ${ }^{9}$ proposed the applicatio of radical surgical measures, the operation bein $\vec{g}_{\vec{W}}$ performed within the first 24 to 48 hours from the onset of haemorrhage; his reported operativg mortality for early cases was $5 \%$. Gordon-Taylor 1 . commented: 'Finsterer's first 48 hours is still theे optimum period for surgical attack in haematemesis and the golden age of gastric surgery will have been attained only when all cases of haemorrhage from chronic ulcer come to operation within that space of time'. And Tanner ${ }^{23}$ found that the bes? results were obtained by early and frequent surgery. While the mortality with medica management can be as low as the $2.5 \%$ achieve $\phi$ by Meulengracht, ${ }^{15}$ it is unlikely that a universa surgical approach will provide either compara巾lळ success or achieve wide acceptance. In genefal surgical intervention has been limited to selected patients ${ }^{2}, 16,17$ the best results being achieved prompt surgery in patients with proved or probatolo peptic ulcers. Avery Jones, ${ }^{11}$ in a study of 400 consecutive admissions for haematemesis, foun $\bar{\phi}$ particular indications for emergency gastrectom in patients over 50 years with good clinical evidence of chronic ulcer who had brisk recurrent haemor $\overrightarrow{\overline{0}}$ rhage after admission. Probably the most im 3 portant factor influencing mortality in haema temesis is the age of the patient; above 60 years. there is a steep increase in the proportion of deaths from bleeding peptic ulcer and it is in these cases. that the best surgical contribution to the reduction of mortality can be made.

With awareness of the factors influencing mortality in bleeding peptic ulcer, a policy of selective surgical intervention was introduced af the Central Middlesex Hospital in 1946. Surgerp was readily considered in patients known to have. a chronic ulcer if they bled again after admission No patient was denied operation in the face of severe recurrent bleeding, but a much stronge? bias was exerted in favour of operation over thes age of 40. Surgical treatment was undertaken iq patients with a presumed or proven acute ulcer there was severe recurrent bleeding on two or thre occasions accompanied by shock. Although bleed=ing acute ulcer has a very low mortality in younger 
Table 2

Haematemesis and Melaena Annual Mortality-Peptic Ulcer Group

\begin{tabular}{|c|c|c|c|c|}
\hline & & Deaths & & ortality \\
\hline $\begin{array}{l}1941 \\
1942 \\
1943 \\
1944 \\
1945 \\
1946\end{array}$ & $\begin{array}{r}52 \\
71 \\
92 \\
106 \\
124 \\
118\end{array}$ & $\left.\begin{array}{r}5 \\
2 \\
4 \\
9 \\
8 \\
11\end{array}\right\}$ & $\begin{array}{l}5.7 \% \\
6.6 \% \\
7.9 \%\end{array}$ & $\begin{array}{l}\text { Medical } \\
\text { policy }\end{array}$ \\
\hline $\begin{array}{l}1947 \\
1948 \\
1949 \\
1950 \\
1951 \\
1952 \\
1953 \\
1954 \\
1955 \\
1956 \\
1957\end{array}$ & $\begin{array}{r}91 \\
113 \\
136 \\
119 \\
203 \\
188 \\
179 \\
176 \\
186 \\
153 \\
195 \\
2,302\end{array}$ & $\left.\begin{array}{r}9 \\
6 \\
9 \\
15 \\
13 \\
16 \\
16 \\
12 \\
7 \\
7 \\
7 \\
8\end{array}\right\}$ & $\begin{array}{l}7.4 \% \\
9.4 \% \\
7.4 \% \\
7.9 \% \\
4.1 \%\end{array}$ & $\begin{array}{l}\text { Selective sur- } \\
\text { gical policy }\end{array}$ \\
\hline
\end{tabular}

people, the mortality is appreciable over the age of 60.12

As Tanner ${ }^{22}$ has stressed, the criterion for success or failure of a surgical policy is its influence on overall mortality and not the mortality for surgical intervention as such, which depends on the type of risk accepted. The result of the adoption of selective surgical treatment at the Central Middlesex Hospital is shown in Table 2 which indicates that the overall mortality from bleeding peptic ulcer has been reduced to $4 \%$.

Further analysis of the figures showed that patients with recurrent bleeding at any age from gastric ulcers, and those bleeding from duodenal ulcers over the age of 60 have particularly benefited from a surgical policy. Chronic gastric ulcer is a particularly strong indication for surgery; bleeding from this source carries a high mortality under medical treatment and its operative arrest by gastrectomy is generally easier than is the surgery of bleeding chronic duodenal ulcer. Though these figures cover only those patients with proved or probable peptic ulcer, there are many other possible causes of severe gastro-intestinal haemorrhage which may require surgical intervention, such as tumours of the stomach, vascular lesions of the intestine, diverticular disease, and portal hypertension.

The success of any surgical approach to the treatment of haematemesis requires close cooperation between physicians and surgeons if, as seems proper, patients continue to be admitted to medical wards. In every case all evidence of chronic peptic ulcer from previous investigation must be considered in conjunction with the history before admission in order to assist the final choice between operative and conservative treatment. The adoption of a policy whereby early diagnosis of the cause of bleeding can be achieved ${ }^{6}, 7$ greatly facilitates correct appraisal.

If operation be decided upon, a little time may be allowed to improve the patients' condition by blood transfusion unless bleeding be so profuse as to permit no delay. The surgical treatment of bleeding peptic ulcer requires an experienced gastric surgeon and preferably a senior anaesthetist. There is a risk of aspiration into the lungs and it is important that a cuffed endotracheal tube be inserted quickly. It is equally important for the surgeon to remove all blood clot from the stomach at operation to minimize the danger of postoperative vomiting and inhalation.

Partial gastrectomy is the operation of choice in all patients; local suture of bleeding points, or local excision of a gastric ulcer have little to recommend them. Any lesser operation than gastric resection is usually futile. There is a difficult problem facing the surgeon who is forced to operate in the face of massive recurrent haemorrhage when no lesion can be identified. The abdomen should never be closed if the surgeon is satisfied that the blood is coming from the upper reaches of the gut and not from lower down; either a wide gastrotomy for inspection and palpation of the gastric mucosa should be made-a prolonged and sometimes uncertain procedureor a 'blind' gastrectomy performed. In the latter case the ulcer responsible for bleeding will be found in almost every patient on opening the resected specimen.

\section{Tracheotomy and Gastrectomy}

Severe chronic bronchitis and emphysema is a constantly recurring clinical accompaniment of haematemesis. Such cases can present formidable operative risks and so bias the physician against operation that medical measures are persisted with despite every evidence that only surgical treatment can stop the bleeding. It is in these cases of severely impaired respiratory function that tracheotomy, done at the time of gastrectomy, can transform the post-operative outlook by making efficient bronchial drainage possible with intermittent suction and by improving ventilation. Experience at the Central Middlesex Hospital in a small number of cases has been encouraging, and in most instances the tracheotomy tube can be removed in 7 to ro days. An alternative approach, successfully applied by Schooling and Simon, ${ }^{20}$ was by use of artificial respiration with a Beaver Mark 2 respirator connected to a short cuffed endotracheal tube inserted via a tracheotomy through which bronchial toilet was performed with 
intermittent suction. This method has the advantage over tracheotomy alone of ensuring adequate respiration in patients whose ventilating function depends almost entirely on diaphragmatic movement, and who pass into severe respiratory distress after an upper abdominal operation.

\section{Treatment of Bleeding Oesophageal Varices}

The development and subsequent rupture of oesophageal varices constitute the most important complication of portal hypertension. In Britain emergency admission to hospital because of bleeding from this cause is relatively infrequent $(3 \%$ of all admissions to the Central Middlesex Hospital for haematemesis and melaena) compared with American experience where as many as $12.5 \%$ of admissions for upper gastro-intestinal haemorrhage have been ascribed to portal hypertension. ${ }^{19}$

Bleeding from oesophageal varices is usually severe and exsanguinating, most often originating in the region of the oesophago-gastric junction. In patients whose portal hypertension depends on extra-hepatic portal vein obstruction the prognosis is good, and once bleeding has stopped there is usually a rapid return of good health. In patients with cirrhosis, however, haemorrhage is notoriously difficult to control and is only too often followed by deepening jaundice, ascites and coma. There is, therefore, every reason to arrest haemorrhage in cirrhosis with the least delay.

Temporary control of haemorrhage from oesophageal varices can be obtained in most cases by means of compression with the triple-lumen Sengstaken-Blakemore tube. This is inserted until the gastric balloon is well below the cardia and inflated with $100 \mathrm{ml}$. of water. The inclusion of '20 ml. 'Hypaque' contrast medium enables its position in the stomach to be easily located by portable plain X-ray film of the abdomen and gentle traction on the tube is sufficient to anchor the balloon at the cardia, this position being maintained by strapping to the cheek with adhesive plaster. Traction on the tube using a pulley system and weights may be dangerous and is unnecessary. The oesophageal balloon is next inflated to a pressure of 20 to $30 \mathrm{~mm}$. of mercury. The gastric balloon compresses the upper part of the stomach against the diaphragm and controls bleeding from the submucosal plexus of veins in the region of the cardia whilst the oesophageal balloon helps to anchor the tube in addition to exerting direct pressure on oesophageal varices. The third lumen of the tube should be used for feeding the patient with $20 \%$ glucose solution, for instilling neomycin, potassium supplements and purgatives and for diagnostic aspiration. If bleeding continues, as judged by blood staining of the aspirated gastric contents, it is reasonable to assume that the haemorrhage is originating elsewhere, often fron? an associated gastric or duodenal ulcer. This maȳ sometimes be confirmed by the introduction of $\bar{a}$ radio-opaque medium such as ' Gastrografin ' int $\mathbb{D}$ the stomach via the tube, using the technique. described by Chandler et al. ${ }^{\text {? }}$

It is always difficult to decide on the appropriate time for removal of the tube. The procedure is not without risk, and the dangers of asphyxia from the inflated balloon slipping up into the pharynx and of gastric and oesophageal ulceration increase the longer the tube is left in position\% Generally the oesophageal balloon is deflated $b$ after 24 hours and it is advisable that decompression be carried out in the morning so that if there is recurrent haemorrhage this can be dealt with as a day-time emergency and not in the early hours. 3 Before withdrawal it is wise policy to leave the apparatus lying in situ before aspirating the gastrico balloon and removing the tube, to ensure that bleeding has stopped.

There is perhaps no other emergency in which general medical treatment, in addition to theo measures adopted to control bleeding, are of such importance. Adequate blood transfusion is essential and oxygen may be required to combato cerebral anoxia. Hypoprothrombinaemia may bes a factor disturbing the clotting mechanism in these patients and vitamin $K$ should be administergd parenterally. The prevention of coma is of firsto importance and this risk can be minimized Eyy. reducing intestinal bacterial activity with neomy aing $2 \mathrm{~g}$. four times a day. The administration of ans enema will help to remove as much as possible of blood from the bowel. Both diuretics ${ }^{1}$ and pituitrin $^{21}$ have been shown to be effective in loweringo portal pressure and both are worthy of trial.

The patient who continues to bleed despite all medical measures presents a formidable problem, for there is no reliable emergency surgical measure for dealing with life-threatening haemorrhage. Indeed, in many patients the bleeding is only one of many abnormalities incidental to liver failurej and a fatal termination. The construction of a porto-caval shunt is a long procedure which theo severely-ill cirrhotic patient is poorly fitted to withstand. Probably some lesser procedure, suche as ligation of the varices, or Tanner's operation ${ }^{23}$ in which the left gastric vessels are ligated and? divided, the upper stomach transected and tho ends anastomosed again, is the best method of achieving a more than temporary control of the situation, but the mortality is still high. Should $\mathbb{E}^{\circ}$ the patient's condition improve sufficiently, con-0 sideration can then be given at a later date to a venous shunt operation but, despite early en-क thusiasm for these procedures, it seems likely that ${ }^{\text {s }}$ the prognosis of the bleeding cirrhotic patient is 
determined by the disease in the liver rather than by the pressure in the portal vein.

\section{REFERENCES}

I. ATKINSON, M. (1959), Lancet, ii, 819.

2. BOHN, G. (1949), Brit. med. F., ii, 630 .

3. CHANDLER, G. N., and WATKINSON, G. (1953), Lancet, ii, 1170 .

4. CHANDLER, G. N., and WATKINSON, G. (1958), Quart. F. Med., 27, 564

5. CHANDLER, G. N., and WATKINSON, G. (I959), Ibid., 28, 37 I.

6. CHANDLER, G. N., CAMERON, A. D., NUNN, A. H., and STREET, D. F. (I960a), Gut, I, 6.

7. CHANDLER, G. N., CAMERON, A. D., NUNN, A. H., and STREET, D. F. (I960b), Lancet, ii, 507.

8. CROHN, B. B. (1950), Univ. West. Ont. med. f., 20, 98.

9. FINSTERER, H. (1939), Surg. Gynec. Obstet., 63, 291.

10. GORDON-TAYLOR, G. (1935), Lancet, ii, 81 I.

I I. JONES, F. AVERY (1947), Brit. med. f., ii, 44I.
12. JONES, F. AVERY, and GUMMER, J. W. P. (1960), ' Clinical Gastroenterolozy'. Oxford: Blackwells.

13. LEVEEN, H. H., PASTERNACK, H. S., LUSTRÏN, 1. SHAPIRO, R. B., BECKER, E., and HELFT, A. E. (1960),
\%. Amer. med. Ass., r73, 770.

14. MEULENGRACHT, E. (1935), Lancet, ii, 1220.

15. MEULENGRACHT, E. (1947), Arch. int. Med., 80, 697.

16. PARSONS, K. O., and ALDRIDGE, L. W. (1951), Brit. $\mathcal{~}$. Surg., 38, 370.

17. PEDERSEN, J. (1951), Lancet, i, 1292.

18. POLLARD, A., and SUMMERSKILL, W. H. J. (1960), Brit. med. \%., i, I7I.

19. SCHIFF, L., and SHAPIRO, N. (1951), 'Peptic Ulcer'. Philadelphia: W. B. Saunders Co.

20. SCHOOLING, I. B., and SIMON, L. (1958), Brit. F. Surg., 46,86 .

21. SCHWARTZ, S. I., BALES, H. W., EMERSON, G. L., and MAHONEY. E. B. (1959), Surgery, 45, 72.

22. TANNER, N. C. (1950), Proc. roy. Soc. Med., 43, 147.

23. TANNER, N. C. (1954), Postgrad. med. $\mathcal{F}$., 30, 577.

24. TIBBS, D. J. (1956), Lancet, ii, 266.

25. WITTS, L. J. (1937), Brit. med. F., i, 847.

\section{HAEMATOLOGY}

(Postgraduate Medical Journal, September 1959)

Price 6s. 6d. post free

THE DIFFERENTIAL DIAGNOSIS OF HAEMOLYTIC ANAEMIAS

George Discombe, M.D., B.Sc.

THE RELATIONSHIP BETWEEN GENETIC, NUCLEAR AND SOCIAL SEX

William M. Davidson, M.D., and Shirley Winn, B.Sc.

CELL COUNTS

J. W. Stewart, M.B., B.S., and P. J. CroslandTaylor, M.B., B.Chir.

THE ASSESSMENT OF PLATELET FUNCTION

A. A. Sharp, M.D., B.Sc.
THE DIAGNOSIS AND MANAGEMENT OF HAEMOPHILIA AND CHRISTMAS DISEASE

M. C. G. Israels, M.Sc., M.D., F.R.C.P., F. Nour-Eldin, Ph.D., M.B., L.S.A., and John F. Wilkinson, M.Sc., Ph.D., M.D., F.R.C.P., F.R.I.C.

\section{HAEMORRHAGIC STATES}

E. K. Blackburn, M.D., F.R.F.P.S.

ATYPICAL PERNICIOUS ANAEMIA

Allan Jacobs, M.D.

Published by

THE FELLOWSHIP OF POSTGRADUATE MEDICINE

9, Great James Street, London, W.C.1 